\title{
Factors Influencing Intentions to use Digital Learning during COVID-19 Outbreak in Sindh: An Empirical Study
}

\author{
Abdul Rahim Chandio \\ chandiorahim@gmail.com
}

\begin{abstract}
This study aims to determine the intention of the students towards the use of digital learning during the COVID-19 outbreak as it impacts to cover the syllabus and face the learning management at risk. The rising dilemma of the COVID-19 urged the world communities to adopt the Digital system in the learning sphere to mitigate the psychological stress of the pandemic as Pakistan also moved to meet the criteria accordingly. The current research investigates the university students' perception to apply the digital learning system in the way to regulate their online classes among the graduate to the Ph.D. level in Sindh. For the discovering the opinion of the digital learning users the behavioral determinants as perceived ease of use (PEOU), perceived usefulness (PU), social influence (SI), perceived quality (PQ), and intention to use e-learning (IEL) have been proposed and these constructs are used to envisage the students intentional level to use the wireless technology in their online classes in a Pakistan point of view. The data was collected through the students using an online survey of the Mehran University of Engineering \& Technology Jamshoro, in which 249 respondents participated via their online feedback to fill the questionnaires. The theoretical approach pursues to encircle the technological acceptance model and unified theory of acceptance and use of technology to find out the users intention to use the digital learning and the data analysis was carried out through utilizing SPSS version 24 and the hypotheses were tested through the regressions and correlations. The given results highlight that all proposed factors reveal the significant and positive relationship with dependent variable. The limitation of the prevailing study is concerned with the use of wireless technology in educational sector within a particular institution and findings could assist the students to adopt the online learning during the COVID-19 outbreak. The overall findings lead towards proposed framework and its practical implications.
\end{abstract}

Keywords: COVID-19, Digital learning, Perceived ease of use, perceived quality

\section{Introduction}

The significance of virtual learning occupied an effective significance and importance across the world during the Covid-19 pandemic outbreak to ensure speedy accessibility and interconnectivity to meet the learning management. Likely, higher education commission (HEC) urges the Pakistanis universities for moving to online classes to stay away from the education loss to the students for their staying at home due to prevailing dilemma of the COVID-19 pandemic and issued the affiliated institutions in the country to adopt the Digital-learning management 
system in the way to mobilize virtual learning activities (Mukhtar,et al.,2020; Shehzadi, et al., 2020). The dearth of infrastructure and poor IT literacy rate in Pakistan becomes a hard task to start an online education system on an urgent basis hence shifting classes online could not mobilize the activities accordingly (Mukhtar,et al., 2020).Several institutions have been brought in the line to initiate the online classes in which the university of Peshawar, Institute of Business Administration (IBA)(Punjab University), Virtual University of Pakistan, Allama Iqbal Open University, and Mehran University of Engineering \& Technology Jamshoro, etc. Despite the HEC announcement to launch online and virtual classes at the universities in Pakistan and it urges to well-built learning management systems (LMS) to commence online classes to adopt the advance initiatives to halt the proliferation of COVID-19, no general university in Sindh meet the criteria effectively whereas majority universities in the country have no infrastructure and resources to start virtual classes.

The adoption of an e-learning system offering online instruction which requires infrastructure relating to information technology (IT) as easy accessibility to a computer, internet facility, signal coverage for rural and backward candidates, tendency and motivation of the learner's intention to create a digital environment. the use of information technology can be denied in the cotemporary scientific age of globalization where its significance and popularity in education sector sustain its due place and weightage as the role of e-learning in the academic arena during the ongoing Covid-19 pandemic can assist to raise the educational levels of the students (Abbasi, et al., 2020; Eltayeb, et al., 2020). The flourishing innovative technologies and learning management systems both for teaching and assessment have taken a headway providing a utilizable solution for educators and allowing policy makers to implement the use of information technology during the quarantine days for covering the course work (Mukhtar,et al., 2020).

The dire need for the acceptability of the digital learning system pursues the significance and global support to learners and intuitions to adopt the online learning system. Likely, HEC produced the recommendations to the universities to shift toward online learning regarding the quarantine periods in Pakistan which can ensure the provision of the online classes and remote learning activities for students (Shehzadi, et al., 2020). Moreover, HEC urges to equip the universities with the technological infrastructure for remote learning. The culturing of the virtualizing of e-learning Pakistan faces the hurdles and opportunities to make the country a 
digital state particularly in the education sector. Despite the availability of the adequate tool to meet the challenges of distance learning as imposed because of the COVID-19 pandemic but it is preferred to be easy to learn face to face as it is considered a difficult task except for the supervision of a teacher (Gonzalez, et al., 2020; Rodrigues, et al., 2019).

The tool can be used for communication, asking questions, collecting assignments, and posting group projects. The rising of difficulties due to the COVID-19 pandemic university has already started online classes for Masters/Ph. D. programs in April. For the postgraduate programs (Master, M. Phil, and Ph. D.) students' online classes were scheduled from $13^{\text {th }}$ April 2020 and undergraduate classes to be started. All students were urged to follow given instruction while commencing the virtual classes to install office 365 and using the official student ID credential of Mehran University i.e., rollno@student.muet.edu.pk and activate the Microsoft teams applications. The advantages of e-learning can be useful in the impediment of the COVID-19 pandemic and it can encompass remote learning comfort, and accessibility (Mukhtar,et al., 2020). The emergence of the digital atmosphere encircles the limitations as inefficiency and difficulty in maintaining academic integrity which requires a trained faculty on using and organizing online modalities and managing lesson plans with reduced cognitive load and increased interactivities. This role in the academic arena has gained importance furthermore considering the ongoing Covid-19 pandemic causing all educational institutions around the world to close down and thus giving rise to multiple challenges at all stages and levels of education in particular for students (Abbasi, et al., 2020). The adoption of innovative technologies can assist the learning management to meet the time teaching and assessment and provide solutions to educators to execute the information technology to carry out the syllabus in the days of quarantine.

\section{Literature Review}

E-learning encircles the varieties of concepts to include online learning, digital learning, virtual learning, distance learning, mobile learning, and computer-assisted instruction, electronic teaching (e-teaching), mediated learning, and simulation-based learning as these all are based on the digital learning ecosystem (Frehywot, et al., 2013). Electronic learning (e-learning) is a learning process by a virtual means in which online lectures and presentation to disseminate learning activities via the utility of information and communication technologies (ICTs). 
The significance and use of information technology (IT) in every aspect of lives and its increasing recognition in the education sector can be an undeniable reality in the contemporary era of scientific age Chandio, et al 2018; Vitoria, et al.,2018).The vitality of digital learning occupied an important place in the ongoing Covid-19 pandemic that diverted the attention of the world educational institutions to meet the gap of the closing of the faculties (Abbasi, et al.,2020; Chavarría-Bolaños, et al., 2020).

The major stakeholders including the students, teachers, administration, and technological infrastructure can develop significant efforts to continue the virtual learning atmosphere to mobilize the educational process and minimize gaps arising from the contemporary circumstances. There are numerous researchers to support the significance and execution of the electronic learning (e-learning) system (Vitoria, et al., 2018; Govindasamy, 2001) [6-10] and the number of the universities around the world promote the virtual teaching method as the digital learning system have been supported and valued by the learners asto secure the affected students of the closures of the faculties due to Covid-19 pandemic (Chavarría-Bolaños, et al., 2020; Martín-Blas, and Fernández, 2009; Govindasamy, 2001).The existing study is confined to investigate the perception of the students of Mehran University of Engineering \& Technology Jamshoro for the adoption of their virtual classes where students were enrolled and software team, Zoom, Teams, and Skype were provided to assign every course. This study derives the behavioral factors (for instance PEOU, PU, SI, PQ, and IEL) to investigate the users' intention to use e-learning where the users of the virtual learning discover their opinion. The greater part of the research has been conducted to find out the intention to use e-learning and it connects the users' perception with technology use in learning management. The intention is a perception of users to use electronic services in the educational sector and the proposed factors investigate the e-learning users' students' intention to use the system. The proposed construct Perceived ease of use (PEOU) implies the degree of easiness of use to which a user believes that using a particular system would be free of uneasiness to be operated and brought in operation and the construct perceived usefulness (PU) refers the usefulness of the system to carry out the task to be accomplished (Davis,1989). Social influence is a person's perception regarding others to think students should adopt virtual class via innovative technology (Bélanger, and Carter, 2008).Perceived quality (PQ) is the perception to highlight the quality of the technology to be used by the students during their online classes and it defines the perceived value and easy to navigate the e-learning (Chiu, et al., 
2005). In this regard, researchers proposed behavioral factors to determine the perception of elearning users as they users the issues to be faced by digital learning).

\section{Hurdles and Opportunities for e-learning}

The wide-based adoption of e-learning across the world as it is being considered a part of formal education during the spread of Covid-19 due to lockdown situation encouraged its significance and importance to meet the criteria of learning management at the time of risk and incubation. Besides the growing popularity of the digital educational system there are numerous challenges and hurdles in the way of the adoption of e-learning in third world communities particularly in Pakistan as its impediments (Qureshi, et al., 2012). Remote learning is a serious challenge to a technology backward nation due to a lack of adequate financial investment in the development of the virtual learning infrastructure. Poverty and provision of infrastructure support to students is a difficult task and presence of the speedy internet, and availability of digital learning environment is the dire need for a virtual learning procedure whereas students of the rural class in the Mehran University of Engineering \& Technology Jamshoro can face the issue of the similar nature.

Course content issues(course materials available to students through electronic means) also impede the effectiveness of e-learning as implementations innovative classroom experience makes difficult for teacher and student to adjust with innovative environment. The dearth of information technology (IT) training, necessary skills, experienced administration, and available human resources can allow giving birth to challenges to adopting innovative thinking. the number of the researcher argues that the effectiveness of e-learning integration can ensure the guarantee to succeed in the innovative system of e-learning management and it is not an easy task for Pakistan to get benefit fully from the e-learning advantageous under the prevailing condition (Qureshi, et al., 2012).

E-learning allows learners to provide them easy accessibility to the material as they require to their study at their favored rapidity except for the stress of missing important information (Roy \& Raymond, 2005). The adoption of e-learning is based on the low delivery cost as once learning stuff is to be produced and uploaded online which escapes away from the expiry date and can be utilized across the world (Allen, 2011).Virtual learning can propagate the information technology 
(IT) culture that can also assist to eliminate the Bridging the gap between theory and practice. Deep learning can overcome the surface learning due to availability of information and it boosts shared learning and monopoly of ideas follow of a teacher to learners on equally basis and researcher argues that adoption of successful computer-assisted learning requires the degree of proficiency in computer technology (Croxall, \& Cummings, 2000).

\section{Conceptual Framework}

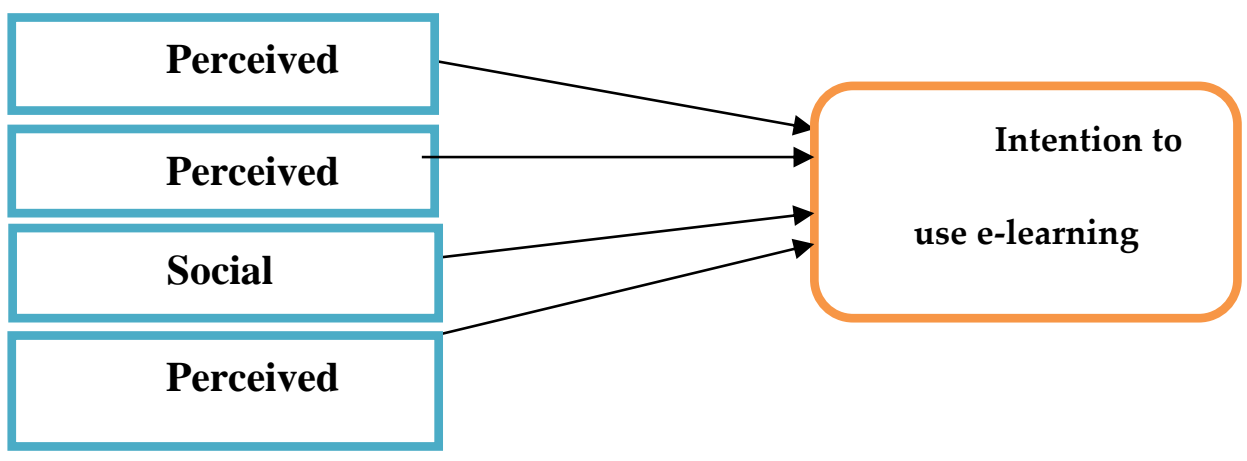

Fig. 1 Proposed conceptual model

Four independent factors (PU, PEOU, SI, and PQ) have been proposed in the existing model to investigate the e-learning users' intention relating to the adoption of virtual classes as these constructs impact the Intention to use e-learning. A behavioral approach of e-learning users' intention regarding adopting the online classes management and education dissemination has relied on one's attitudes and beliefs towards students' perception to use the system.

A theoretical approach has been inculcated in this study in which the factors of the proposed variables have been derived and their relationship has been maintained. the derived determinants in the existing model have been borrowed from the given theories in which, PU and PEOU are present in TAM that was designed by Davis, F.D. (1989), and intention to use has been secured from the unified theory of acceptance and use of technology (UTAUT) (Venkatesh, et al., 2003). The used constructs in the given theories were applied to interpret the technology users' viewpoint and explore the user's intention to use the electronic system as an innovation. 


\section{Hypotheses}

$\mathrm{H}_{1}$. There is a positive and significant relationship between perceived ease of use (PEOU)and Intention to use e-learning (ITEL).

$\mathrm{H}_{2}$ : There is a positive and significant relationship between the perceived usefulness (PU) and Intention to use e-learning (ITEL).

$\mathrm{H}_{3}$ : There is a positive and significant relationship between Social Influence (SI) and Intention to use e-learning (ITEL).

$\mathrm{H}_{4}$ : There is a positive and significant relationship between perceived quality (PQ) and dependent factor Intention to use e-learning (ITEL).

\section{Results and Discussion}

The prevailing research contains quantitative as online survey-based research and crosssectional study. The proposed variables develop hypotheses and sustain their positive relationship as the construct (i.e. PEOU, PU, and PQ) maintain their association with Intention to use e-learning (ITEL) whereas social influence (SI) gives a negative relationship with Intention to use e-learning (ITEL). In the current study data was obtained from the students Mehran University of Engineering $\&$ Technology Jamshoro where data was collected from the (Master, M. Phil, and PhD). Besides, the proposed construct was used by earlier researchers (Venkatesh et al., 2003; Davis,1989) whereas the present study uses these determinants with a slight difference in language and nature of the study as this study is concerned with the interpretation of the e-learning users' perception to apply online classes during the COVID-19 pandemic outbreak. In this study, data collection was used via applying five points Likert scale that encircle the five options as (1) strongly disagree (2) Disagree (3) neutral (4) agree and (5) strongly agree. The existing study pursues the correlation and regression analysis to test hypotheses validity.

Table 1. Demographic characteristics

\begin{tabular}{|c|c|c|c|}
\hline Variables & Description & Frequency & Percentage \\
\hline \multirow{2}{*}{ Gender } & Male & 205 & 82.3 \\
\cline { 2 - 4 } & Female & 44 & 17.6 \\
\hline & $21-30$ & 51 & 20.4 \\
\hline
\end{tabular}




\begin{tabular}{|c|c|c|c|}
\hline Age & $31-40$ & 198 & 79.5 \\
\hline \multirow{2}{*}{ Education } & Master/Bachelor & 230 & 92.2 \\
\cline { 2 - 4 } & M. Phil/ Ph. D. & 19 & 7.6 \\
\hline
\end{tabular}

Table 2. Survey items, standard deviations and mean

\begin{tabular}{|c|c|c|}
\hline Proposed Items & Mean & SD \\
\hline Q1: I make the intention to apply e-learning (ITEL). & 3.691 & .9643 \\
\hline $\begin{array}{l}\text { Q2: I make expectation to pursue the use of virtual } \\
\text { learning system (ITEL). }\end{array}$ & 3.7468 & .85112 \\
\hline $\begin{array}{l}\text { Q3: I envisage a plan to organize the use of electronic } \\
\text { learning (ITEL). }\end{array}$ & 3.7124 & .86536 \\
\hline $\begin{array}{l}\text { Q4: Using e-learning will not be uneasy tome to use it } \\
\text { (PEOU). }\end{array}$ & 3.6652 & .84560 \\
\hline $\begin{array}{l}\text { Q5: The use of electronic learning is the trouble-freefor } \\
\text { to achieve my learning objects (PEOU) }\end{array}$ & 3.7210 & .76245 \\
\hline $\begin{array}{l}\text { Q6: It would easy for learning skills and educational } \\
\text { essentialities via adopting the use of electroniclearning } \\
\text { (PEOU) }\end{array}$ & 3.7897 & .72723 \\
\hline $\begin{array}{l}\text { Q8: E-learning can be helpful for to carry out my } \\
\text { learning process faster (PU) }\end{array}$ & 3.8369 & .76509 \\
\hline $\begin{array}{l}\text { Q9: E-learning services provide me an easiness to } \\
\text { perform my educational activities to be done (PU). }\end{array}$ & 3.8841 & .74241 \\
\hline $\begin{array}{l}\text { Q10: Using electronic learning can develop my } \\
\text { performance and eliminate hindrance to comprehend my } \\
\text { class studies easily (PU). }\end{array}$ & 3.7768 & .78344 \\
\hline $\begin{array}{l}\text { Q14: People influence the user to use the virtual learning } \\
\text { and prefer the digital learning (SI) }\end{array}$ & 3.7124 & .74201 \\
\hline $\begin{array}{l}\text { Q15nfluential people of my society think that I must } \\
\text { adopt the e-learning system (SI) }\end{array}$ & 4.0043 & 2.68215 \\
\hline
\end{tabular}




\begin{tabular}{|l|c|c|}
\hline Q16: the most significant people consider the user that & 3.8155 & .76300 \\
he/she must prefer to adopt the online technological & & \\
system to be beneficial (SI) & 3.7124 & .71840 \\
\hline Q18: It is easy to find the way the e-learning Web site \\
(PQ)
\end{tabular}

The significance of the multivariate correlation is to find out the relationship of the factors.Henceforth, an investigation has been carried out by the researcher to derive the relationship of independent variables and the dependent variable via Pearson's correlation. Results highlights a significant relation at the level of 0.1 that represents constructs of the conceptual model supported whereas one factor as social influence (SI) remained insignificant positively correlated with the criterion variable.

Table 3. Pearson Correlation

\begin{tabular}{|c|c|c|c|c|c|}
\hline & BI & PEOU & TIT & SI & IQ \\
\hline ITEL & 1 & & & & \\
\hline PEOU & $.597^{* *}$ & 1 & & & \\
\hline PU & $.576^{* *}$ & $.507^{* *}$ & 1 & & \\
\hline SI & .260 & $.258^{* *}$ & $.260^{* *}$ & 1 & \\
\hline PQ & $.561^{* *}$ & $.571^{* *}$ & $.554^{* *}$ & $.185^{* *}$ & 1 \\
\hline
\end{tabular}

All variables s correlation sustains between (.258 to .597) whereas the correlation of the PEOU (.597), PU (.576-.507), SI (.258-.260), and PQ (.571-.185) confirmed. in this study highest correlation materializes in the construct (.597) whereas social influence is the lowest one (.258-.260). The multiple regression analysis discovers the impact of independent variables with and a dependent variable or tests the hypothesis as the regression table is given below. 
Table 4. Regression analysis

\begin{tabular}{|c|c|c|c|c|c|c|}
\hline & \multicolumn{6}{|c|}{ Coefficients } \\
\hline & \multirow[t]{2}{*}{ Model } & \multicolumn{2}{|c|}{$\begin{array}{l}\text { Un-standardized } \\
\text { Coefficients }\end{array}$} & \multirow{2}{*}{$\begin{array}{c}\text { Standardized } \\
\text { Coefficients }\end{array}$} & \multirow[t]{2}{*}{$\mathrm{t}$} & \multirow[t]{2}{*}{ Sig. } \\
\hline & & B & Std. Error & & & \\
\hline \multirow{5}{*}{1} & (Constant) & .655 & .302 & & 2.171 & .031 \\
\hline & PEOU & .426 & .082 & .317 & 5.213 & .000 \\
\hline & PU & .379 & .081 & .281 & 4.694 & .000 \\
\hline & SI & .048 & .036 & .065 & 1.317 & .189 \\
\hline & $\mathrm{PQ}$ & .303 & .089 & .212 & 3.410 & .001 \\
\hline
\end{tabular}

Total of 249 respondents gave their responses as participation assisted to carry out this empirical study.0.851 was calculated as Cronbach's alpha of the questionnaire. Overall, $80 \%$ of students have positive perceptions towards e-learning, and the majority of the students use their technology infrastructure to carry out the e-learning process. In the social influence people fail to understand to use and prefer to refer the e-learner users to adopt virtual class as they are unknown towards the use of a digital system of learning that comprises $20 \%$.

Table 5. Hypotheses

\begin{tabular}{|c|c|c|c|c|c|}
\hline Variable & $\begin{array}{c}\text { Stand } \\
\text { beta }\end{array}$ & $t$ value & $\begin{array}{c}\text { Significance } \\
\text { level }\end{array}$ & $\mathrm{H}$ & $\begin{array}{c}\text { Hypothesis } \\
\text { status }\end{array}$ \\
\hline PEOU & .655 & 5.213 & .000 & $\mathrm{H} 1$ & Supported \\
\hline PU & .379 & 4.694 & .000 & $\mathrm{H} 2$ & Supported \\
\hline SI & .048 & 1.317 & .189 & $\mathrm{H} 3$ & Not Supported \\
\hline PQ & .303 & 3.410 & .001 & $\mathrm{H} 4$ & Supported \\
\hline
\end{tabular}

The existing study results present that out of four hypotheses three of them supported whereas one hypothesis has been rejecting. it is recommended to the coming researcher to interpret the social influence factor in the society to discover people's perception regarding the use of the technology and give a preference to adopt the digital system in the learning as the current study is concerned a consideration indicate the higher illiteracy rate that denies the fact to apply the e-learning process. This study urges to explore more other factors to influence the students' perception to adopt an 
innovative learning system (e-learning) and faculties' intentions must be investigated and their experiences to be measured towards e-teaching during the covid-19 pandemic lockdown.

\section{Methodology}

The prevailing study pursues the cross section study and quantitative research methodology applied. Moreover, structured instrument used and survey questionnaires developed as numerous studies adopted the same line of action. Research followed respondents' significance impact in the digital learning and data collection ensured by the university students to use electronic learning system. The demographic section encircled gender, qualification level, and age of students and this study contained 20 items in order to measure the proposed constructs. In addition, survey questionnaires' were written in English language and Questionnaires (items) presented with means and standard Deviation.

\subsection{Sample and Sampling Process}

In this research sampling population has been derived from the students of Mehran University of Engineering \& Technology Jamshoro which represent the intentional level of the digital learners. The population's sampling confined to the respondents of the students of Mehran University of Engineering \& Technology Jamshoro. In this scenario, data was collected by means of using an online survey in which 325 Questionnaires distributed and 249 respondents materialized their online feedback that met $76.6 \%$ and five points Likert scale was brought in use for data collection in which criteria of the Krejcie and Morgan (1970) followed in the point of view

of population sampling. Furthermore, data analysis was carried via SPSS version 24 and the hypotheses were tested through the regressions and correlations to test the relationship of the independent and dependent factor and reveal their effects respectively.

\section{Conclusion}

E-learning is the acquisition and disseminating process of education throughout society. The outcome of the innovative transfer of knowledge is based on e-learning asit deeply influenced with the emergence of information and communication technologies (ICT) and the internet. Despite the intensive popularity of the e-learning system in Pakistan it has not yet totally adopted by the universities across the country in their propagation and disseminating teaching and learning. in Pakistan people face comprehending the true essence of e-learning system as a situation requires government support to boost up the literacy rate and prefer the use of information technology (IT) in the way of learning and e-teaching. Administration and faculty members must apply necessary 
measures to develop e-teaching quality to assist the students to meet their better learning during COVID-19 pandemic lockdown.

\section{Reference}

Abbasi, S., Ayoob, T., Malik, A., \& Memon, S. I. (2020). Perceptions of students regarding E learning during Covid-19 at a private medical college. Pakistan Journal of Medical Sciences, 36(COVID19-S4).

Allen, M. W. (2011). Michael Allen's 2012 e-learning annual. Pfeiffer. ISBN 978-0-470- 91382 6.

Bélanger, F., \& Carter, L. (2008). Trust and risk in e-government adoption. The Journal of Strategic Information Systems, 17(2), 165-176.

Chandio, A. R., Haider, Z., Ahmed, S., Ali, M., \& Ameen, I. (2018). E-government in Pakistan: framework of opportunities and challenges. Gsj, 6(12).

Chavarría-Bolaños, D., Gómez-Fernández, A., Dittel-Jiménez, C., \& Montero-Aguilar, M. (2020). E-Learning in Dental Schools in the Times of COVID-19: A Review and Analysis of an Educational Resource in Times of the COVID-19 Pandemic. Odovtos International Journal of Dental Sciences, 207-224.

Chiu, C. M., Hsu, M. H., Sun, S. Y., Lin, T. C., \& Sun, P. C. (2005). Usability, quality, value and e-learning continuance decisions. Computers \& education, 45(4), 399-416.

Croxall, K., \& Cummings, M. N. (2000). Computer usage in family and consumer sciences classrooms [Electronic Version]. Journal of Family and Consumer Sciences Education, 18(1), 9-18.

Davis, F.D. (1989), "Perceived usefulness, perceived ease of use, and user acceptance of information technology”, MIS Quarterly, Vol. 13 No. 3, pp. 319340.

Eltayeb, L. B., Alharthi, N. S., Elmosaad, Y. M., \& Waggiallah, H. A. (2020). Students' perception on E. Learning and Remote Exams during COVID 19 Outbreak 2020. International Journal of Pharmaceutical and PhytopharmacologicalResearch (eIJPPR), 10(5), 142-148.

Frehywot, S., Vovides, Y., Talib, Z., Mikhail, N., Ross, H., Wohltjen, H., ... \& Scott, J. (2013). E-learning in medical education in resource constrained low-and middle-income countries. Human resources for health, 11(1), 4.

Gonzalez, T., de la Rubia, M. A., Hincz, K. P., Comas-Lopez, M., Subirats, L., Fort, S., \& Sacha, G. M. (2020). Influence of COVID-19 confinement in students performance in higher education. arXiv preprint arXiv:2004.09545.

Govindasamy, T. (2001). Successful implementation of e-learning: Pedagogical considerations. The internet and higher education, 4(3-4), 287-299.

Martín-Blas, T., \& Serrano-Fernández, A. (2009). The role of new technologies in the learning process: Moodle as a teaching tool in Physics. Computers \& Education, 52(1), 35-44. 
Mukhtar, K., Javed, K., Arooj, M., \& Sethi, A. (2020). Advantages, Limitations and Recommendations for online learning during COVID-19 pandemic era. Pakistan Journal of Medical Sciences, 36(COVID19-S4).

Qureshi, I. A., Ilyas, K., Yasmin, R., \& Whitty, M. (2012). Challenges of implementing e learning in a Pakistani university. Knowledge Management \& E-Learning: An International Journal, 4(3), 310-324.

Rodrigues, H., Almeida, F., Figueiredo, V., \& Lopes, S. L. (2019). Tracking e-learning through published papers: A systematic review. Computers \& Education, 136, 87-98.

Roy, A., \& Raymond, L. (2005). e-Learning in support of SMEs: Pipe dream or reality. Proceedings of 5th European Conference on E-Learning (pp. 283).

Shehzadi, S., Nisar, Q. A., Hussain, M. S., Basheer, M. F., Hameed, W. U., \& Chaudhry, N. I. (2020). The role of digital learning toward students' satisfaction and university brand image at educational institutes of Pakistan: a post-effect of COVID-19. Asian Education and Development Studies.

Venkatesh, V., Morris, M.G., Davis, G.B. and Davis, F.D. (2003) 'User acceptance of information technology: Toward a unified view', MIS quarterly,, pp. 425-478.

Vitoria, L., Mislinawati, M., \& Nurmasyitah, N. (2018, September). Students' perceptions on the implementation of e-learning: Helpful or unhelpful?. In Journal of Physics: Conference Series (Vol. 1088, No. 1, p. 012058). IOP Publishing. 